\title{
ОПЫТ ПОСТРОЕНИЯ ГЕОЛОГИЧЕСКОЙ МОДЕЛИ ШТОКМАНОВСКОГО ГАЗОКОНДЕНСАТНОГО МЕСТОРОЖДЕНИЯ С ИСПОЛЬЗОВАНИЕМ ДАННЫХ ЗD СЕЙСМОРАЗВЕДКИ
}

Ажпилов Ю.П., Тимонин А.Н., Шаров С.А., Штейн Я.И. (ВНИИГАЗ)

\section{Аннотация.}

Для изучения морских месторождений характерно отсутствие достаточного количества разведочных скважин. Поэтому сушественным дополнением при построении детальных постоянно действующих геологических моделей могут являться данные сейсморазведки 3D. B дальнейшем существующие модели могут использоваться как для подсчета запасов и обоснования категорийности запасов, так и послужить базисом для разработки сценариев добыни углеводородов.

Экспресс-переинтерпретация сейсмических данных 3D. Данные, используемые нами при построении геологической модели Штокмановского ГКМ (ШШКМ), содержали дополнительные резервы для улучшения интерпретации, как структурной, так и динамической. Поэтому была предпринята попытка более детально построить основные поверхности: кровли и подошвы продуктивных пластов. Уверенно проследить удалось поверхности вблизи кровли $Ю_{0}$, вблизи кровли $Ю_{1}$ и вб́лизи подошвы $\mathrm{O}_{2}$.

Кровлю $Ю_{0}$ удалось прокоррелировать в автоматическом режиме. Стали заметны концентрические осложнения вб́лизи купола структуры и новые направления возможных малоамплитудных нарушений на восточном фланге. Кровля $Ю_{1}$ была прослежена в полуавтоматическом режиме, однако выполненные построения можно считать вполне кондиционными и достоверными. С использованием этой корреляции был проведен расчет ряда сейсмических атрибутов для кровлей горизонтов $Ю_{0}$ и $Ю_{1}$. Карты атрибутов продуктивного пласта $Ю_{0}$ показали яркое пятно в поле среднеквадратичных амплитуд и мгновенных частот, связанное с газовой залежью. Конфигурация яркого пятна в плане практически совпадает с контуром газоносности, полученного по структурным построениям. Такое очевидное «свечение» залежи в поле атрибута снимает всякие сомнения в продуктивности месторождения жа участке с категориями запасов $\mathrm{C}_{2}$ в западной части. Аномалии для пласта $Ю_{1}$ в поле атрибутов не столь очевидны.

Основные характеристики модели. Первым шагом при построении геологической модели ШГКМ является описание пространственного расположения разломов с помощью «пилларов» - вертикальных, линейных, листрических или искривленных линий, состоящих из точек, соединенных отрезками прямых или кривых. Набор пилларов задает конфигурацию плоскости разлома. Модель разломов генерируется на основании полигонов разломов, полученных при сейсмической интерпретации, и импортированных структурных карт.

На следующем этапе моделирования происходит создание пространственного скелета модели, определяющего форму и размеры ячеек в плане. Геометрия ячеек каркаса определяется положением разрывных нарушений. Стороны ячеек в результаге построения будут ориентированы субпараллельно поверхностям разломов. Для настройки геометрии ячеек применяется задание трендов и направлений. разломных линий. Результат построения (структурный каркас) представляет собой серию пилларов, по одному для угла каждой ячейки. Созданный на этом этапе каркасный трехмерный грид определяет скелет модели, в который будут вставлены горизонты, задающие границы слоев ячеек. В завершение процесса построения структурной модели создается «3D грид», содержащий трехмерные ячейки, которые в дальнейшем наполняются различными значениями свойств. Для каждой продуктивной зоны в модели был задан соответствующий уровень ГВК. Моделирование свойств выполнено непрерывно, включая водонасыщенную зону, до границ модели. Скважинные данные, на основе которых построена модель свойств были загружены в виде попластовых разбивок с вычисленными свойствами для интервалов-коллекторов. Для прослоев-неколлекторов при моделировании заданы постоянные значения, условно прннятые ниже вычисленных граничных значений параметров. Перед построением модели свойств был осуществлен процесс перемасштабирования исходных скважинных данных для приведения их в соответствие с вертикальным разбиением модели на слои ячеек. Значения свойств в ячейках, соответствующих скважинам, вычислены с взвешиванием по моцности. Создание модели свойств было проведено на основе загруженных и перемасштабированных скважинных данных. В качестве основного метода моделирования распределения пористости и песчанистости, исходя из представительности исходных данных, было выбрано стохастическое моделирование (Sequential Gaussian Simulation). Необходимо отметить, что помимо структурных поверхностей в результате интерпретации данных сейсморазведки 3D были получены прогнозные значения пористости для пластов $Ю_{0}, Ю_{1}$ и $Ю_{2}$, которые были загружены в модель и использовались при построениях как вспомогательные в качестве основы для ко-кригинга (co-kriging) c соответствуюшими весовыми коэффициентами. Для каждого продуктивного интервала месторождения было выполнено по 10 реализаций моделирования свойств с последующим осреднением полученных значений.

\section{Заключение.}

На основании построенной модели Штокмановского месторождения впервые в практике ГКЗ был утвержден прирост запасов углеводородов промышленньх категорий без бурения дополнительных разведочньх скважин. Это свндетельствует о правильности полученных решений и корректности выполненных построений и подсчетов, что дополнительно подтвердила пробуренная впоследствии разведочная скважина.

Дальнейшие действия заключаются в построении гидродинамической модели и ее использовании при проектировании разработки этого уникального месторождения. 